\title{
PROGNOSTIC VALUE OF NON-REACTIVE BURST SUPPRESSION EEG PATTERN ASSOCIATED TO EARLY NEONATAL SEIZURES
}

\author{
Magda Lahorgue Nunes', Maria Margarida Giraldes², \\ Ana Paula Pinho', Jaderson Costa da Costa ${ }^{3}$
}

\begin{abstract}
Seizures are the most frequent neurological event in newborns and clinical data suggest that etiology is the dominant factor in long term outcome. However, there are consistent background EEG abnormalities associated to neonatal seizures that are usually related to unfavorable outcome as the burst - suppression pattern. Objective: The objective of this study was to correlate clinical and EEG features associated to long - term outcome of newborns with non - reactive burst - suppression (BS) EEG. Method: Newborns included in the study were selected from our database and had conceptional age (at the time of first EEG) $>37$ weeks, EEG recordings with non - reactive BS available for review and clinical follow up. Results: 12 newborns met inclusion criteria, $50 \%$ had seizures in the first day of life. Seizures became refractory to treatment in all of them. In $50 \%$ the etiology of seizures was considered cryptogenic, $33 \%$ had inborn errors of metabolism and $17 \%$ had clinical history and neuroimage suggestive of hypoxic-ischemic encephalopathy. The follow-up showed that 7/12 infants deceased, 3 during the first year of life, and one in the neonatal period. All the survivors had severe developmental delay and multifocal neurological impairment. $92 \%$ developed refractory epilepsy, $58 \%$ were latter diagnosed with West syndrome. Conclusion: The non-reactive BS pattern may appear related to many neonatal neurological disorders and is associated with early and refractory neonatal seizures. It is clearly associated with elevated morbidity and mortality and to the development of post-neonatal epilepsy.
\end{abstract}

KEY WORDS: neonatal EEG, neonatal seizures, burst-suppression pattern, neonatal epileptic syndromes.

\section{Valor prognóstico do EEG com padrão de surto-supressão não reativo associado a convulsões neonatais precoces}

RESUMO - Convulsões representam o evento neurológico mais freqüente no período neonatal e a etiologia das crises parece ser o aspecto clínico mais associado ao prognóstico a longo prazo. Entretanto, existem padrões anormais de EEG, que de forma consistente relacionam-se a prognóstico, entre eles o padrão de surto - supressão. Objetivo: Este estudo teve como objetivo correlacionar aspectos clínicos e eletroencefalográficos associados a prognóstico em longo prazo de recém - nascidos (RN) com padrão de surto - supressão não reativo no EEG. Método: Foram selecionados para este estudo RN com EEG neonatal realizado no Laboratório de Neurofisiologia Clínica do Hospital São Lucas da PUCRS e acompanhados na mesma instituição, com idade concepcional superior a 37 semanas (na data do EEG), cujos registros estivessem disponíveis para revisão. Resultados: Foram incluídos 12 RN, $50 \%$ apresentaram crises convulsivas a partir do primeiro dia de vida. Em todos as convulsões eram refratárias ao tratamento medicamentoso. Em $50 \%$ a etiologia foi considerada criptogênica, 33\% apresentavam erros inatos do metabolismo e 17\% tinham história clínica e achados de neuroimagem sugestivos de encefalopatia hipóxico - isquêmica. O seguimento clínico demonstrou que 7/12 evoluíram para óbito, sendo 3 durante o primeiro ano de vida e um no período neonatal. Os sobreviventes apresentavam grave comprometimento do desenvolvimento neuropsicomotor e déficits neurológicos múltiplos, 92\% seguiram com epilepsia refratária e 58\% evoluíram para síndrome de West. Conclusão: O reconhecimento de padrão de surto - supressão não reativo no EEG neonatal pode ser relacionado a diversas doenças neurológicas e é associado a convulsões precoces e refratárias. Existe também definida associação entre este padrão e elevada morbi-mortalidade neonatal além do desenvolvimento de epilepsia pós-neonatal.

PALAVRAS-CHAVE: EEG neonatal, convulsões neonatais, síndromes epilépticas neonatais, surto - supressão.

Clinical Neurophysiology Laboratory - Hospital São Lucas and Division of Neurology, PUCRS School of Medicine, Porto Alegre RS, Brazil: ${ }^{1}$ Associate Professor of Neurology and Pediatrics, PUCRS School of Medicine; ${ }^{2}$ EEG Fellows, Laboratory of Clinical Neurophysiology Hospital São Lucas PUCRS; ${ }^{3}$ Professor of Neurology, PUCRS School of Medicine.

Received 24 May 2004, received in final form 14 August 2004. Accepted 2 October 2004.

Dra. Magda Lahorgue Nunes - Serviço de Neurologia - Hospital São Lucas, PUCRS - Avenida Ipiranga 6690/220 - 90610-000 Porto Alegre RS - Brasil. E-mail: nunes@pucrs.b 
Seizures are the most frequent neurological event in newborns ${ }^{1}$. Furthermore, the incidence of seizures in the neonatal period is greater than at any other period of life, ranging from 1.8 to $5.1 / 1000$ live births ${ }^{2-4}$. The outcome of newborns with seizures has been evaluated by many authors in previous studies ${ }^{5-8}$. There is no clear consensus on how seizures per se are responsible for long term neurological or cognitive sequelae. However, clinical data suggest that etiology is the dominant factor in long term outcome. The incidence of epilepsy following neonatal seizures has been estimated in previous studies and it varies from $17 \%$ to $30 \%{ }^{9-14}$. Since the early manuscript from Monod ${ }^{15}$ many other studies concerning the power of neonatal EEG to predict neurological outcome have been developed. There are consistent background EEG abnormalities that are usually associated to unfavorable outcome as low voltage and burst - suppression pattern (BS) ${ }^{15-21}$.

BS, an abnormal EEG pattern, included among the broad spectrum of discontinuity in neonatal $E E G$, is termed reactive when it can be interrupted by stimulation ${ }^{22,23}$ and non reactive in the contrary, this last pattern has been traditionally associated with unfavorable outcome ${ }^{15,21,24,25}$. BS pattern is also the hallmark of two specific epileptic neonatal syndromes, early myoclonic encephalopathy and early infantile epileptic encephalopathy ${ }^{26,27}$. And it can also happen associated to severe central nervous system disorders such as perinatal asphyxia, inborn errors of metabolism, acquired or congenital infection, dysgenesis.

The aim of this study was to evaluate clinical and EEG features associated to long - term outcome of newborns with early - seizures and non- reactive burst - suppression EEG.

\section{METHOD}

Patients - This retrospective transversal study included infants admitted in the Neonatal Intensive Care Unit of the Hospital São Lucas (University Hospital from PUCRS School of Medicine, Porto Alegre -RS) between January 1984 and June 2002. From our EEG database we selected all infants with early seizures and burst-suppression pattern in the first neonatal EEG. To be included in the study, newborns should have conceptional age (at the time of first EEG) $>37$ weeks, EEG recordings available for review and follow up in our Pediatric Neurology outpatient clinic.

Perinatal data were extracted from medical records and included gestational age, concepcional age at the firs burst- suppression EEG, Apgar score in the $1^{\text {st }}$ and $5^{\text {th }}$ minute of life, birth weight, sex, age of first seizure, type and frequency of seizures, neurological examina- tion, laboratory screening for metabolic and infectious disorders and report of neuroimage studies.

For outcome analyzis we considered the development of post-neonatal epilepsy, neurodevelopment delay and decease. Neuropsychomotor development was based on report of clinical neurological examination and results of Denver II screening test ${ }^{28}$.

EEG recordings - The EEGs were performed on a 16 channel EEG and consisted of 11 channels of EEG, electro-oculogram, submental electromyogram, nasal and abdominal respiratory monitoring and electrocardiogram. Paper speed was $15 \mathrm{~mm} / \mathrm{s}$, and for the EEG we used the time constant of $0.3 \mathrm{~s}$; sensitivity $10 \mu \mathrm{v} / \mathrm{mm}$ and 70 $\mathrm{Hz}$ high linear frequency filter. The electrodes were placed based on the 10-20 system as modified for newborns ${ }^{29}$. The states of the newborn and all the movements during the exam were recorded on the paper by the technician. Each exam lasted at least 50 minutes (or until a complete sleep cycle was recorded). In the cases where a video - EEG was available seizures observed by the technicians were reviewed. A neurophysiologist expert in neonatal EEG unaware of the outcome retrospectively reviewed EEGs.

For analysis we considered the definition of burst suppression pattern as: periods of inactive background that may last from 2 to 10 seconds usually, interrupted by high voltage bursts lasting 1 - 10 seconds, composed of mixed features: irregular delta and theta waves with variable amounts of interspersed spikes and sharps waves $^{21}$ (Fig 1).

In each EEG (one per newborn), we evaluated different parameters including mean burst duration, maximal amplitude of the burst, amount of spikes in the burst, mean duration of the interburst interval, maximal duration of the interburst interval, presence of electroencephalographic seizures and presence of sharp waves in the interburst ${ }^{19}$.

The predominant interburst interval duration was defined as the mean interburst interval duration within a given EEG. Mean burst duration, mean interburst interval duration and maximal burst duration were mesured in seconds, maximal amplitude of the burst was measured in microvolt, the amount of spikes among the burst was visually counted ${ }^{19}$.

For statistical analysis the outcome was related to clinical and EEG features by means of bivariate analysis (Student's T test, Fischer's exact test and $\chi^{2}$ ).

This study is part of the project" Risk factors for developing epilepsy after neonatal seizures", approved by the ethical and scientific committees of our institution. Ethical issues concerning retrospective studies were followed in this protocol.

\section{RESULTS}

During the study period 706 high-risk newborns were submitted to neonatal EEGs. Among 
them $30(4.2 \%)$ presented at least one EEG with burst-suppression pattern and 12 met the inclusion criteria of our study. The group consisted of $7 \mathrm{fe}-$ male and 5 male babies, with Apgar scores varying from 4 to 9 at the $1^{\text {st }}$ minute and 4 to 10 at the $5^{\text {th }}$ minute of life. The birth weight varied from 1750 to 3665 grams. Clinical characteristics and follow up of the newborns are described on Table 1.

All newborns started with seizures during the first week of life and half of them had seizures in the first day of life. Most of the newborns presented more than one type of seizures, in all newborns seizures become refractory to treatment with antiepileptic drugs. The most prevalent type of seizure was focal tonic.

Evaluating neurological status all patients had an obvious encephalopathy from birth with marked hypotonia and hypoactivity. Mechanical ventilation was required in $4(33 \%)$.

Neuroimage studies were available for review in 10 children. $6 / 10$ computed tomography (TC) we- re considered within normal limits, two had white matter hipodensity, one enlarged ventricles and one periventricular calcifications. Besides the $\mathrm{CT}$ scan, 2 newborns were submitted to brain magnetic resonance image (MRI), which confirmed previous findings.

After an extensive evaluation for possible etiology of seizures in 6 newborns it was considered cryptogenic, 4 had inborn errors of metabolism and 2 had clinical history and neuroimage suggestive of hypoxic - ischemic encephalopathy.

The follow-up showed that 7/12 infants deceased, three during the first year of life, and one in the neonatal period. Duration of follow up in the survivors varied from 12 to 24 months as expressed on Table 1. All the survivors had severe developmental delay and multifocal neurological impairment in the moment of the last evaluation. Eleven newborns (92\%) developed refractory epilepsy, and 7 of them (58\%) were latter diagnosed with West Syndrome.

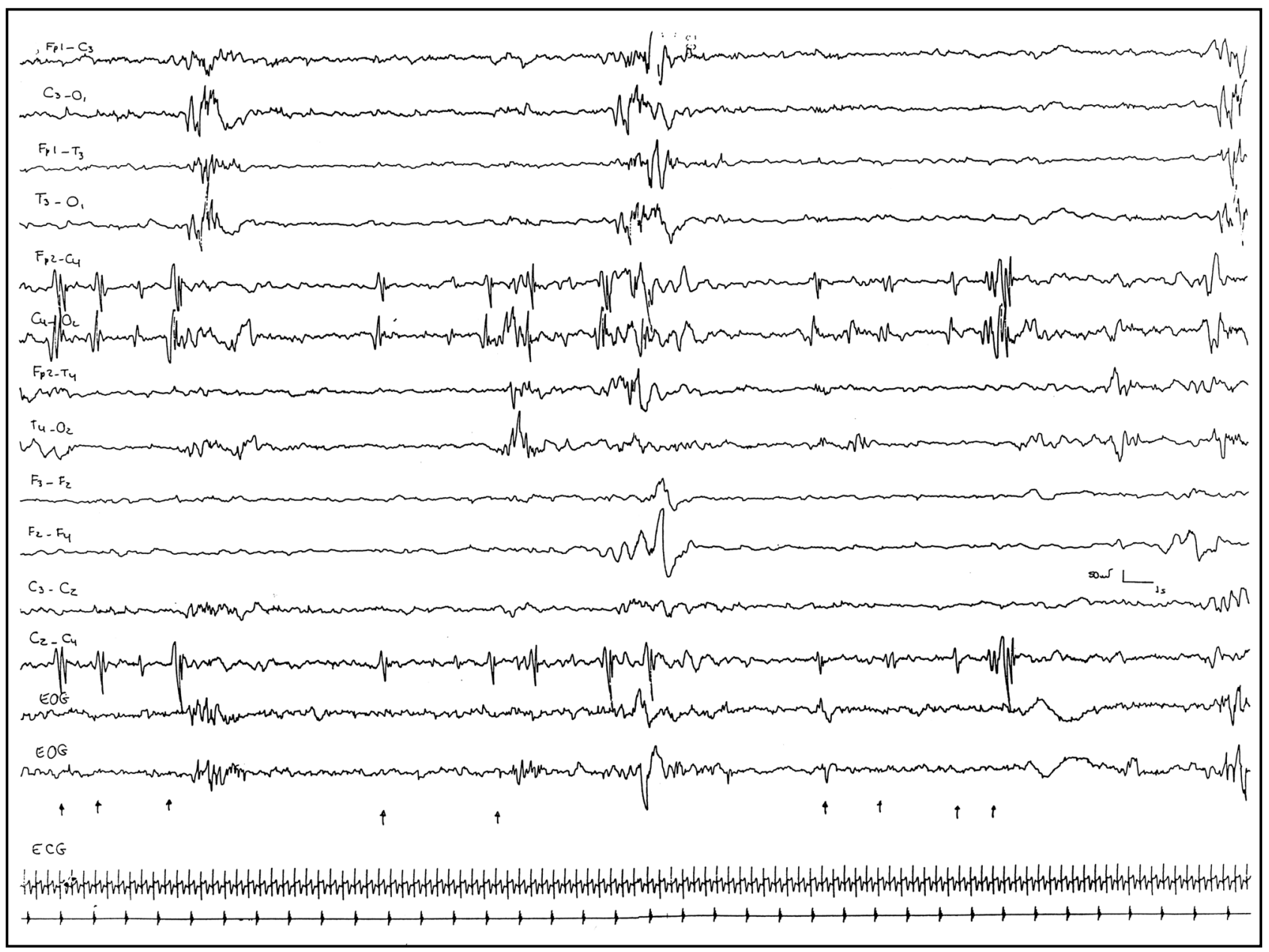

Fig 1. Neonatal EEG showing burst suppression pattern in a newborn with multiple seizures type, refractory to antiepileptic drugs. Arrows indicate myoclonic seizures. $15 \mathrm{~mm} / \mathrm{s}$. 


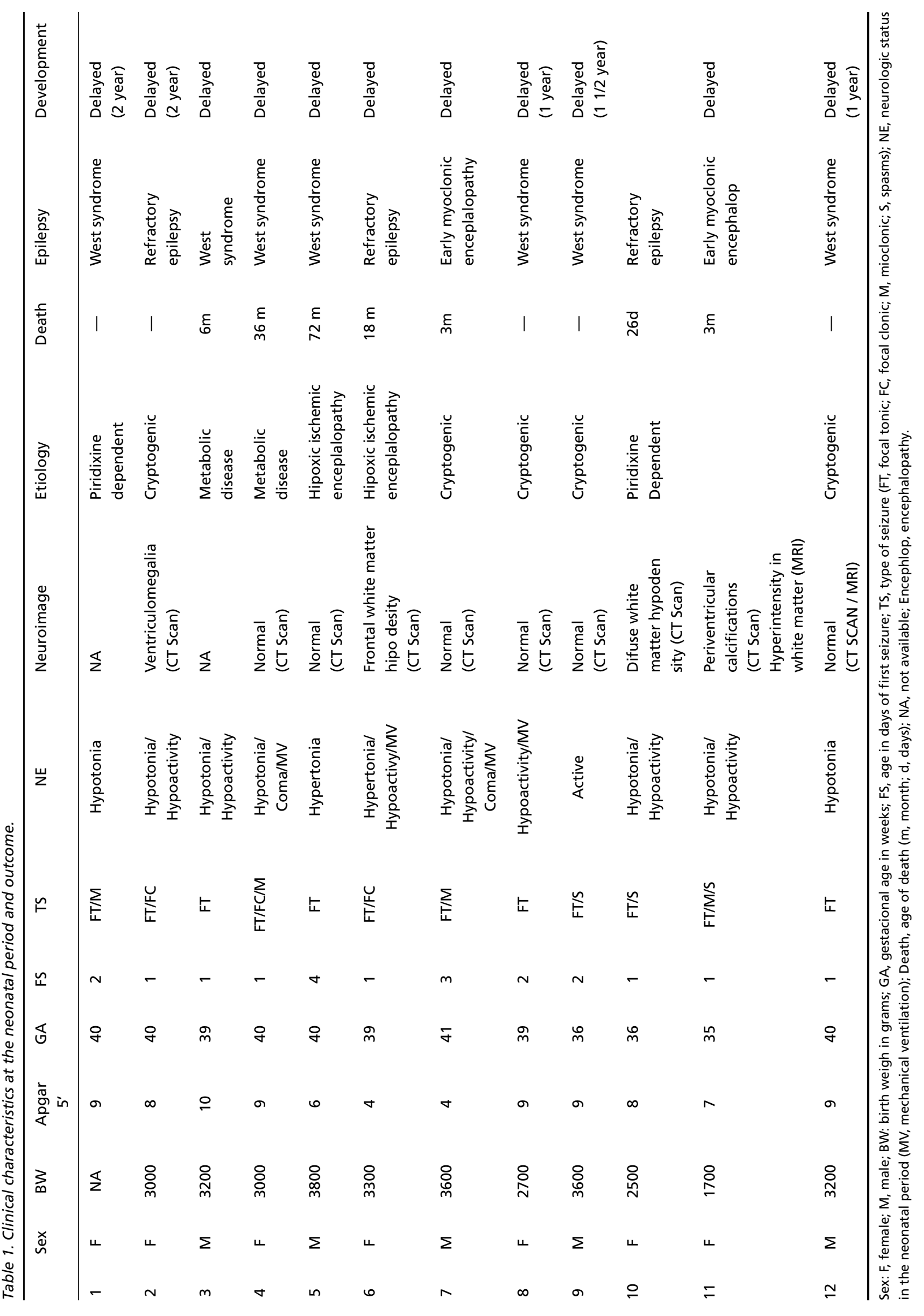


Table 2. Neonatal EEG and follow up EEG.

\begin{tabular}{|c|c|c|c|c|c|c|c|c|c|c|c|}
\hline & GA & CA & $\mathrm{MIBI}$ & MAXIBI & $\begin{array}{l}\text { Sharp } \\
\text { IB }\end{array}$ & $\begin{array}{c}\text { Burst } \\
\text { amp }\end{array}$ & $\begin{array}{l}\text { Burst } \\
\text { Spike }\end{array}$ & $\begin{array}{c}\mathrm{M} \\
\text { Brust }\end{array}$ & $\begin{array}{c}\text { EEG } \\
\text { Sz }\end{array}$ & $\begin{array}{c}\text { Follow-up } \\
\text { EEG }\end{array}$ & $\begin{array}{c}\text { Age } \\
\text { Follow } \\
\text { EEG }\end{array}$ \\
\hline 1 & 40 & $41 w 6 d$ & 7.5 & 20 & No & $>150$ & $>3$ & 3 & Yes & Hypsa-rrhythmia & $1 \mathrm{y} 10 \mathrm{~m}$ \\
\hline 2 & 40 & $42 w$ & 2.0 & 3 & Yes & $<150$ & $<3$ & 2 & No & Multifocal & $1 \mathrm{y} 8 \mathrm{~m}$ \\
\hline 3 & 39 & $40 w 5 d$ & 6.0 & 15 & No & $>150$ & $>3$ & 2 & No & Hypsa-rrhytmia & $6 m$ \\
\hline 4 & 40 & $40 w 1 d$ & 5.5 & 10 & No & $<150$ & $>3$ & 5.5 & No & Hypsa-rrhytmia & $3 y$ \\
\hline 5 & 40 & $42 w$ & 4.0 & 7 & No & & $>3$ & 4 & Yes & Hypsa-rrhytmia & $18 m$ \\
\hline 6 & 39 & $41 w$ & 4.0 & 8 & No & $>150$ & $>3$ & 2 & No & Burst-Suppression & $1 \mathrm{~m}$ \\
\hline 7 & 41 & $42 w$ & 2.0 & 7 & Yes & $>150$ & $>3$ & 7 & No & Burst-Suppression & $3 m$ \\
\hline 8 & 39 & $42 w$ & 2.0 & 7 & No & $<150$ & $>3$ & 4.5 & No & Multifocal & $10 \mathrm{~m}$ \\
\hline 9 & 36 & $38 w$ & 3.0 & 8 & No & $<150$ & $>3$ & 2 & No & Hypsa-rrhytmia & $1 \mathrm{y} 4 \mathrm{~m}$ \\
\hline 10 & 36 & $38 w$ & 2.5 & 7 & No & $>150$ & $>3$ & 4 & No & Multifocal & $20 d$ \\
\hline 11 & 35 & $42 w$ & 21 & 75 & Yes & $>150$ & $>3$ & 2 & Yes & Burst-Suppression & $2 m$ \\
\hline 12 & 40 & $40 w$ & 3.0 & 8 & Yes & $>150$ & $>3$ & 3.5 & Yes & Hypsa-rrhytmia & $6 \mathrm{~m}$ \\
\hline
\end{tabular}

GA, gestational age in weeks; CA, conceptional age in weeks and days; MIBI, mean interburst duration; MAXIIBI, maximum interburst duration; SharplB, presence of sharp waves among IBI; Burst amp, amplitude of burst microvolts; Burst Spike, number of spikes in each burst; $M$ Burst, mean burst duration; EEG Sz, electrographic seizure).

EEG features analyzed showed mean interburst duration ranging from $3-21$ seconds $(5.2 \pm 5.2)$, maximal interburst duration from 3 to 20 seconds $(8.9 \pm 4.4)$, mean burst duration from 2 to 7 seconds (3.4 \pm 1.6$)$. Burst amplitude was higher than $150 \mu \mathrm{V}$ on $7 / 12$ EEGs. Electrographic seizures were observed on 4 EEGs (33\%), sharp waves during the interburst interval were recorded in $4 \mathrm{EEGs}(33 \%)$, in $11 \mathrm{EEGs}$ the burst had more than 3 spikes (92\%).

All newborns in our sample had abnormal follow up EEGs ( $3 / 12$ had persistent burst-suppression, 6/12 developed hypsarhythmia, 3/12 multifocal spikes) (Tabela 2).

The results of the bivariate analysis comparing clinical outcome to EEG features did not showed significant association between the parameters studied.

\section{DISCUSSION}

In this paper we have reviewed clinical and EEG characteristics of newborns with early refractory seizures and non - reactive BS pattern. As expected we have find that this pattern is associated to unfavorable outcome. Mortality and morbidity among these newborns was significantly higher when compared to our whole cohort of newborns with neonatal seizures ${ }^{8,14}$.

Since the first descriptions of this EEG pattern authors have already related it to an unfavorable outcome ${ }^{25-27}$. In a recently study the follow up of newborns with BS pattern was evaluated and authors observed a less unfavorable outcome in newborns with reactive BS pattern ${ }^{20}$; however, their group with non reactive BS had an outcome similar to our study. Holmes and Lombroso ${ }^{21}$ have previously suggested a more favorable outcome associated to reactive BS pattern.

To establish a predictive value for BS pattern some investigators emphasize the importance of the amplitude of the electrical activity between the bursts ${ }^{15,21}$, whereas others emphasize the duration of the interburst interval as the main criterion ${ }^{19,22}$. Menache and coll. ${ }^{19}$ analyzing discontinuous EEGs observed that interburst intervals longer than 30 seconds were related to unfavorable neurological outcome and epilepsy. In our study we have not registered interburst intervals longer than $20 \mathrm{sec}-$ onds. However, all EEGs had evident epileptogenic discharges.

Considering other EEG parameters evaluated, as all newborns from our sample had an unfavorable outcome, the statistical analysis was not able to show significant differences EEG - related.

Spreafico and coll. ${ }^{30}$ have suggested as a possible pathophysiologic mechanism for BS pattern 
impairment in apoptosis that would lead to a condition for cortical disconnection. This finding may probably explain the generation of burst-suppression in newborns with idiopathic neonatal epileptic encephalopaties. However, in cases where multiple insults have damaged specific cortical and subcortical regions as shown by $\mathrm{Aso}^{24}$, the proposed disconnection may happen due to structural impairment.

In conclusion, the non-reactive BS pattern may appear related to many neonatal neurological disorders and is associated with early and refractory neonatal seizures. It is clearly associated with elevated morbidity and mortality and to the development of post-neonatal epilepsy.

\section{REFERENCES}

1. Lombroso CT. Neonatal seizures: a clinician's overview. Brain Develop 1996;18:1-28

2. Lanska MJ, Lanska DJ, Baumann RJ, et al. A population - based study of neonatal seizures in Fayette County, Kentucky. Neurology 1995;45:724-732.

3. Ronen GM, Penney S. The epidemiology of clinical neonatal seizures in Newfoundland Canada: a five-year cohort. Ann Neurol 1995;38:518-519.

4. Saliba RM, Annegers JF, Mizrahi EM. Incidence of clinical neonatal seizures. Epilepsia 1996;37:(Suppl 5):S13.

5. Lombroso CT. Prognosis in neonatal seizures. Adv Neurol 1983;34:101-113.

6. Legido A, Clancy RR, Berman PH. Neurologic outcome after electroencephalographically proven neonatal seizures. Pediatrics 1991;88:583-596.

7. Mc Bride M, Laroia N, Guillet R. Electrographic seizures in neonates correlate with poor neurodevelopmental outcome. Neurology 2000;55:506-513.

8. Nunes ML, Da Costa JC, Godinho CG, Rodrigues MP. Outcome of newborns with seizures: clinical and polysomnographic features. JLBE 1994;7:27-30.

9. Ellenberg JH, Hirtz DG, Nelson KB. Age at onset of seizures in young children. Ann Neurol 1984;15:127-134.

10. Clancy RR, Legido A. Postnatal epilepsy after EEG-confirmed neonatal seizures. Epilepsia 1991;32:69-76.

11. Scher MS, Aso K, Beggarly M, Hamid MY, Steppe DA, Painter MJ. Electrographic seizures in preterm and full - term neonates: clinical correlates, associated brain lesions, and risk for neurologic sequelae. Pediatrics 1993;91:128-134

12. Ortibus EL, Sum JM, Hahn JS. Predictive value of EEG for outcome and epilepsy following neonatal seizures. Electroencephalogr Clin Neurophysiol 1996;98:175-185.
13. Bye AME, Cunningham CA, Chee KY, Flanagan D. Outcome of neonates with electrographically identified seizures, or at risk of seizures. Pediatr Neurol 1997;16:225-231.

14. Da Silva LFG, Nunes ML, Da Costa JC. Risk factors for epilepsy after neonatal seizures. Pediatr Neurol 2004;30.

15. Monod N, Pajot N, Guidasci S. The neonatal EEG : statistical studies and prognostic value in fullterm and preterm babies. Electroencephalogr Clin Neurophysiol 1972;32:529-544.

16. Biagioni E, Bartelena L, Boldrini A, Cioni G, Giancola S, Ipata AE. Background EEG activity in preterm infants: correlation of outcome with selected maturational features. Electroencephalogr Clin Neurophysiol 1994;91:154-162.

17. Nunes ML, Da Costa JC, Taufer L, Da Silveira CMD. Relationship of EEG, neurological diseases and follow up in preterm newborns. Arq Neuropsiquiatr 1995;53:625-630.

18. Oliveira AJ, Nunes ML, Haertel LM, Reis FM, Da Costa JC. Duration of rhythmic EEG patterns in neonates: new evidence for clinical and prognostic significance of brief rhythmic discharges. Clin Neurophysiol 2000;111:1646-1653.

19. Menache CC, Bourgeois FDB, Volpe JJ. Prognostic value of discontinuous EEG. Pediatr Neurol 2002;27:93-101.

20. Douglass LM, Wu JY, Rosman P, Stafstrom CE. Burst - suppression electroencephalogram pattern in the newborn: predicting the outcome. J Child Neurol 2002;17:403-408.

21. Holmes GL, Lombroso CT. Prognostic value of background patterns in the neonatal EEG. J Clin Neurophysiol 1993;10:323-352.

22. Grigg-Damberger MM, Coker SB, Halsey CL, Anderson CL. Neonatal burst-suppression: its developmental significance. Pediatr Neurol 1989;5:84-92.

23. Holmes GL, Rowe J, Hafford J. Significance of reactive burst-suppression following asphyxia in full term infants. Am J Dis Child 1983;137:21-25.

24. Aso K, Scher MS, Barmada M. Neonatal electroencephalography and neuropathology. J Clin Neurophysiol 1989;6:103-123.

25. Pezzani C,Radvanyi E,Bouvet MF, Reilier JP, Monod N. Neonatal electroencephalography during the first twenty-fours hours of life in fullterm newborn infants. Neuropediatrics 1986;17:11-18.

26. Aicardi J, Goutières F. Encephalopathie myoclonique néonatale. Rev Electroencéphalogr Neurophysiol (Paris) 1978;8:99-101.

27. Ohtahara S, Ishida T, Oka E. On the specific age-dependent epileptic syndrome: the early infantile epileptic encephalopathy with suppression - burst. No to Hattatsu 1976; 8: 270-280.

28. Frankenburg WK, Dodds J, Archer P, Shapiro H, Bresnick B. The Denver II: a major revision and restandardization of the Denver Developmental Screening Test. Pediatrics 1992;89:91-97.

29. Curzi L, Mirmiran M. Manuel de techniques d 'enregistrement et d'analyse des stades de sommeil et de veille chez le prematurá et le nouveau - né à terme.Paris: Editions INSERM, 1996.

30. Spreafico R, Angelini L, Binelli S et al. Burst supression and impairment of neocortical ontogenesis: eletroclinical and neuropathologic findings in two infants with early myoclonic encephalopathy. Epilepsia 1993;34:800-808. 